\title{
Glomerular podocytes in diabetic renal disease
}

\author{
Paweł Podgórski ${ }^{1, A-E}$, Andrzej Konieczny ${ }^{3, A, D-F}$, Łukasz Lis ${ }^{1, A, C, E}$, Wojciech Witkiewicz ${ }^{1, E, F}$, Zbigniew Hruby ${ }^{1,2, A-F}$ \\ ${ }^{1}$ Voivodeship Specialty Hospital, Center for Research and Development, Wrocław, Poland \\ ${ }^{2}$ Faculty of Health Sciences, Wroclaw Medical University, Poland \\ ${ }^{3}$ Department of Nephrology and Transplantation Medicine, Wroclaw Medical University, Poland \\ A - research concept and design; $B$ - collection and/or assembly of data; $C$ - data analysis and interpretation; \\ $\mathrm{D}$ - writing the article; $\mathrm{E}$ - critical revision of the article; $\mathrm{F}$ - final approval of the article
}

Address for correspondence

Zbigniew Hruby

E-mail: z.hruby@wp.pl

\section{Funding sources}

None declared

\section{Conflict of interest \\ None declared}

Received on August 17, 2018

Reviewed on 0ctober 26, 2018

Accepted on February 18, 2019

Published online on December 18, 2019

\begin{abstract}
Diabetic nephropathy (DN) is the most common cause of end-stage renal disease (ESRD), both in the USA and in Europe; moreover, its incidence is rising worldwide. The main laboratory markers of DN progression are albuminuria and a reduction in glomerular filtration rates, although progression of the disease has been observed even in the absence of these biomarkers. Renal impairment, associated with diabetes, results from damage to the glomerular filtration barrier, at the level of highly differentiated glomerular epithelial cells: podocytes. These cells regulate glomerular filtration and many immunological processes occurring at this level. The earliest possible diagnosis of diabetic kidney disease (DKD) and implementation of intensive treatment offers the possibility of preventing or substantially delaying the onset of ESRD. In this article, we review various urinary biomarkers linked with glomerular podocyte cytophysiology as potentially sensitive diagnostic tools for the early detection of DKD. These biomarkers have predictive potential for assessing the progression toward end-stage nephropathy.
\end{abstract}

Key words: pathogenesis, diabetic kidney disease, podocytes

\section{Cite as}

Podgórski P, Konieczny A, LisŁ, Witkiewicz W, Hruby Z.

Glomerular podocytes in diabetic renal disease.

Adv Clin Exp Med. 2019;28(12):1711-1715.

doi:10.17219/acem/104534

DOI

10.17219/acem/104534

\section{Copyright}

Copyright by Author(s)

This is an article distributed under the terms of the

Creative Commons Attribution Non-Commercial License

(http://creativecommons.org/licenses/by-nc-nd/4.0/) 
Diabetic kidney disease (DKD) or diabetic nephropathy (DN) is a clinical entity developing in patients suffering from diabetes mellitus type 1 or 2 , defined as albuminuria (30-300 $\mathrm{mg} / 1 \mathrm{~g}$ creatinine in the morning urine sample), worsening of glomerular filtration and arterial hypertension. The prevalence of DN has grown steadily in recent years due to a massive increase of the incidence of diabetes type 2. The International Diabetes Federation forecasts an increase in the number of patients with diabetes mellitus from 285 million worldwide in 2010 to 385 million in $2030 .{ }^{1}$ Diabetic kidney disease is the most frequent cause of end-stage renal disease (ESRD), both in Europe ${ }^{2}$ and in the USA. ${ }^{3}$ In the next decade, the increase is expected to continue. In 2025 the prevalence of diabetic ESRD is predicted to amount to $3.2 \%$ per year. ${ }^{4}$

Early diagnosis of DN enables the implementation of strategies preventing progression of chronic renal disease and reducing the risk of potentially lethal cardiovascular injury. Moreover, Fioretto et al. have demonstrated that even established histopathological changes are reversible by normoglycemia following successful pancreatic transplantation in DKD patients. ${ }^{5}$

Currently, the main laboratory markers of DKD progression are albuminuria and glomerular filtration rate (GFR). Nevertheless, at the early stages of DN albuminuria is absent and GFR is elevated. Perkins et al. reported that during a 6-year follow-up of 386 patients with diabetes type 1 , regression to normal albumin excretion levels was observed in the majority of patients (58\%). ${ }^{6}$ The classical model of DN proposed by Mogensen has been modified: In the new DN phenotype, deterioration of GFR is not related to rise of albuminuria, and can even be seen in its absence.

The weakness of albuminuria as a biomarker of DN progression is underscored by observations of significant histopathological alterations in DN with a virtual absence of albuminuria. Therefore, it is not advisable to rely solely on albuminuria and GFR in monitoring disease activity or establishing a prognosis in DKD. At present, no alternative biomarkers of the disease are available. Alternative biomarkers should be sufficiently specific and sensitive for $\mathrm{DN}$ without being invasive and expensive. Establishing such markers would permit a significant cohort of patients to be identified at a very early stage of the disease, when albuminuria and GFR are normal, yet the probability of developing full-blown $\mathrm{DN}$ is imminent.

This manuscript presents alternative biomarkers of DKD linked with glomerular visceral epithelial cells: podocytes.

\section{The role of podocytes in diabetic kidney disease}

Podocytes are differentiated cells lining the external surface of the glomerular basement membrane (GBM). They consist of 3 distinct parts: the cell body, major processes and foot processes (FPs). The FPs of neighboring podocytes interdigitate, forming a meshwork called a slit diaphragm (SD), an ultimate barrier to prevent urinary protein loss. ${ }^{8-10}$ The main function of podocytes is therefore to participate in the formation of the filtration barrier and to regulate glomerular filtration, along with the GBM and the endothelium. Podocytes also mechanically support the glomerular vascular bud, participate in the metabolic turnover of the GBM and take part in the immunological processes at the glomerular level.

The development of DN is highlighted by the accumulation of extracellular matrix, the proliferation of mesangial cells and damage to the GBM. These changes are followed by alterations in the renal tubules, interstitium and arterioles. The ultimate changes include sclerotization of the glomerular tufts and fibrosis of the interstitium. ${ }^{11}$

Damage to the podocytes leads to a loss of their adhesive properties and is a principal cause of DN progression. ${ }^{12,13}$ It has been demonstrated that the number of glomerular visceral epithelial cells is reduced in diabetes type 1 , even after a short disease duration. ${ }^{14}$ Moreover, an analysis of the histopathological results of renal biopsies in Pima Indians with diabetes type 2 revealed widening of the FPs, coupled with reductions in the number of podocytes. ${ }^{15}$ A morphometric study performed by Dalla Vestra et al. among type 2 diabetes patients determined that diminishment of podocyte density is a more adequate correlate of albuminuria than reduction in the total podocyte number. ${ }^{16}$

Mature podocytes have limited proliferative capacities in situ. ${ }^{17}$ Losses of up to $20 \%$ of podocytes result in proliferation of the mesangial cells, whereas more substantial losses cause denudation of the GBM with subsequent glomerular fibrosis and increased proteinuria. ${ }^{18}$

Another compensatory mechanism of podocyte injury is their ability to regenerate from progenitor cells, namely glomerular parietal epithelial cells (PEC) and renin-secreting arteriolar wall cells. ${ }^{19}$

It has been demonstrated that podocytes are being excreted in the urine of patients with glomerulopathies, and that the magnitude of podocyturia correlates with the disease activity. ${ }^{20,21}$

\section{Podocyte-dependent pathogenic pathways leading to glomerular injury in DN}

Podocyte loss initiating glomerular hypertrophy and subsequent sclerosis may result from hyperglycemia-induced generation of reactive oxygen species (ROS) causing podocyte apoptosis. ${ }^{22}$ Changes in glomerular cells are interrelated: endothelial nitric oxide (NO) synthase deficiency may be responsible for podocyte loss resulting in glomerulosclerosis. ${ }^{23}$

Autophagy in podocytes is a homeostatic process enabling lysosomal degradation of obsolete proteins and cell organelles. Chronic exposure to high glucose 
concentrations leads to impairment in autophagy with subsequent lysosome insufficiency and podocyte apoptosis, causing development of DN. ${ }^{24}$ Thus, activation of autophagy in podocytes may serve as a therapeutic intervention to prevent the progression of DKD.

Poor control of diabetes results in a constant elevation of circulating growth hormone $(\mathrm{GH})$ concentrations, and functional $\mathrm{GH}$ receptors are expressed on podocyte cell membranes. As a result, podocyte hypertrophy ensues, accounting for progressive podocyte aberrations leading to the detachment of the $\mathrm{GBM}^{25}$ with consequent glomerulosclerosis. High levels of GH are equally implicated in kidney hypertrophy and proteinuria during early DN. ${ }^{26}$ Growth hormone contributes to renal sclerosis by promoting the synthesis and accumulation of extracellular matrix components. ${ }^{27}$ Yet another mechanism of podocyte depletion due to $\mathrm{GH}$ activity in early $\mathrm{DN}$ is programmed cell death, or apoptosis. Its pathogenesis is linked to 2 possible mechanisms: $\mathrm{GH}$-induced generation of ROS, ${ }^{28}$ or exposure to transforming growth factor beta (TGF- $\beta$ ), also resulting from high GH levels. ${ }^{29}$

Epithelial-to-mesenchymal transition (EMT) consists of the acquisition of mesenchymal characteristics by epithelial cells, specifically by proximal tubular cells and podocytes. As a result, these cells undergo transformation to extracellular matrix protein-generating myofibroblasts that initiate and perpetuate fibrosis of renal tissue. Epithelial-to-mesenchymal transition in podocytes results in abnormalities of their functioning, leading to impairment of glomerular filtration. ${ }^{30}$ Studies in experimental diabetes have demonstrated phenotypical changes in podocytes: the replacement of an epithelial marker (nephrin) by a mesenchymal marker (desmin). ${ }^{31}$ In human studies of podocytes secreted in the urine and renal biopsy specimens of type 2 diabetes patients, it has been demonstrated that a rise in podocyte EMT markers is directly correlated with the clinical and pathological severity of the disease. ${ }^{32}$

Sphingolipid accumulation occurs in glomerular diseases, including DN. Sphingomyelin phosphodiesterase acid-like C3b (SMPDL3b) is expressed in podocytes, where it modulates danger signaling ${ }^{33}$ and is linked with the pathogenesis of DN. The intracellular composition of sphingolipids in podocytes impacts the progression of the disease. It has been determined that there is a link between sphingolipid accumulation and glomerular proliferation and hypertrophy in DKD. ${ }^{34}$ The accumulation of ceramide seen in apoptotic cells is related to the podocytopenia observed in DKD.

\section{Methods of quantitative and qualitative assessment of podocyturia}

Methods for evaluating podocyte injury include histopathological examination of renal biopsy specimens or cytological assessment of podocytes excreted in the urine, taking into account the number, membrane protein expression, mRNA, exosomes, and microRNA. ${ }^{22}$ Kidney biopsy is still regarded as the "gold standard" in diagnosing renal parenchymal diseases. Although percutaneous biopsy is widely utilized and relatively safe, certain complications may ensue, such as bleeding from the puncture site or fistula formation. Therefore, attempts have been made to employ the evaluation of urinary podocytes as a diagnostic tool in DKD, since it is a method that is safe, widely available and fully reproducible. The initial approach to the evaluation of urinary podocytes was to establish a culture of podocytes recovered from urinary sediment, with the aim of assessing the expression of their membrane proteins using immunofluorescent visualization. ${ }^{35,36}$ It was soon demonstrated that assessment of podocyte antigen expression immediately after the recovery of the cells from urinary sediment by adhesion to a plastic surface provides a useful tool to investigate the importance of podocytes in the progression of glomerular diseases. ${ }^{37}$

The concentration of proteins secreted to the urinary space by damaged podocytes can be measured using the western blot technique. In patients with diabetes, the urinary podocalyxin concentration is higher than the cut-off value in patients at the normoalbuminuric, microalbuminuric and macroalbuminuric stage. ${ }^{38}$

Another way of identifying biomarkers specific to podocytes is to assess mRNA for proteins derived from podocytes in the urine with the real-time polymerase chain reaction (RT-PCR) method. ${ }^{39}$ Wang et al. in a study based on 21 biopsyproven cases of DN, showed a correlation between glomerular podocyte number and intra-renal expression of nephrin, podocin and synaptopodin. The number of glomerular podocytes was also significantly correlated with the urinary expression of synaptopodin, but not with other targets. ${ }^{39}$

In another study, expressions of nephrin, podocin, synaptopodin, WT-1, and alpha actinin-4 were higher in patients with DN than in the normal controls. Urinary nephrin and synaptopodin expressions were correlated with baseline proteinuria or renal function, while WT-1 expression was related to the degree of histological damage. ${ }^{40}$

In recent years, new diagnostic methods like proteomics and peptidomics have gained importance. Rossing et al. used a panel of biomarkers that allowed them to distinguish diabetes subjects with nephropathy with 97\% sensitivity and specificity. ${ }^{41}$ This panel of biomarkers also identified patients who had microalbuminuria and diabetes and progressed toward overt DN over 3 years. In another study, collagen fragments were shown to be prominent biomarkers 3-5 years before the onset of macroalbuminuria. ${ }^{42}$

\section{Summary}

Despite notable improvements in treatment efficacy in recent years and constant broadening of knowledge on the pathogenesis of DKD, end-stage renal failure in the course of DN still remains a challenging problem. 
As described in this article, the widely employed, noninvasive biomarkers of DKD such as albuminuria and impairment of glomerular filtration may be insufficient for early diagnosis of diabetic renal injury. More adequate information can be provided by the histopathological features of percutaneous renal biopsies, although the indications for this procedure in the early phase of DN are disputable; moreover, biopsies are invasive and impose the risk of potential complications. As result, alternative diagnostic methods are being evaluated. Growing evidence of the pivotal role of podocytes in the pathogenesis of DN has attracted attention to markers of injury to these cells. The biomarkers of podocytopathy can be quite easily assessed in urine sediment. The expression of proteins linked with podocyte injury or mRNA can be determined using currently available methods such as western blot or RT-PCR.

Future clinical research should focus on validating and confirming the importance of urinary DKD biomarkers with particular emphasis on the early clinical stages of the disease. Up-to-date therapeutic strategies do not bring about complete remission of DN and concentrate on stopping or slowing down the progression of the disease. The earliest possible diagnosis of this entity and implementation of intensive treatment has the potential to prevent or substantially delay the onset of ESRD.

\section{ORCID iDs}

Andrzej Konieczny (1) https://orcid.org/0000-0002-4966-9771 Paweł Podgórski @ https://orcid.org/0000-0002-2225-3469 Łukasz Lis (10) https://orcid.org/0000-0002-4075-6924 Wojciech Witkiewicz (10 https://orcid.org/0000-0002-4194-1160 Zbigniew Hruby (1) https://orcid.org/0000-0002-1369-4705

\section{References}

1. Shaw JE, Sicree RA, Zimmet PZ. Global estimates of the prevalence of diabetes for 2010 and 2030. Diabetes Res Clin Pract. 2010;87(1):4-14.

2. Kramer A, Pippias M, Noordzij M, et al. The European Renal Association - European Dialysis and Transplant Association (ERA-EDTA) Registry Annual Report 2015: A summary. Clin Kidney J. 2018;11(1):108-122.

3. Saran R, Robinson B, Abbott KC, et al. US Renal Data System 2017 Annual Data Report: Epidemiology of kidney disease in the United States. Am J Kidney Dis. 2018;71(3 Suppl 1):A7.

4. Kainz A, Hronsky M, Stel VS, et al. Prediction of prevalence of chronic kidney disease in diabetic patients in countries of the European Union up to 2025. Nephrol Dial Transplant. 2015;30(Suppl 4):iv113-118.

5. Fioretto P, Steffes MW, Sutherland DE, Goetz FC, Mauer M. Reversal of lesions of diabetic nephropathy after pancreas transplantation. NEngl J Med. 1998;339(2):69-75.

6. Perkins BA, Ficociello LH, Silva KH, Finkelstein DM, Warram JH, Krolewski AS. Regression of microalbuminuria in type 1 diabetes. NEngl J Med. 2003;348(23):2285-2293.

7. Pugliese G. Updating the natural history of diabetic nephropathy. Acta Diabetol. 2014;51(6):905-915.

8. Greka A, Mundel P. Cell biology and pathology of podocytes. Annu Rev Physiol. 2012;74:299-323.

9. Mundel P, Shankland SJ. Podocyte biology and response to injury. J Am Soc Nephrol. 2002;13(12):3005-3015.

10. Mundel P, Kriz W. Structure and function of podocytes: An update. Anat Embryol (Berl). 1995;192(5):385-397.

11. Hayden MR, Whaley-Connell A, Sowers JR. Renal redox stress and remodeling in metabolic syndrome, type 2 diabetes mellitus, and diabetic nephropathy: Paying homage to the podocyte. Am J Nephrol. 2005;25(6):553-569.
12. Steffes MW, Schmidt D, McCrery R, Basgen JM; International Diabetic Nephropathy Study Group. Glomerular cell number in normal subjects and in type 1 diabetic patients. Kidney Int. 2001;59(6):2104-2113.

13. Pagtalunan ME, Miller PL, Jumping-Eagle $S$, et al. Podocyte loss and progressive glomerular injury in type II diabetes. J Clin Invest. 1997; 99(2):342-348.

14. Kriz W. Podocyte is the major culprit accounting for the progression of chronic renal disease. Microsc Res Tech. 2002;57(4):189-195.

15. Lemley KV. A basis for accelerated progression of diabetic nephropathy in Pima Indians. Kidney Int Suppl. 2003;83:S38-42.

16. Dalla Vestra M, Masiero A, Roiter AM, Saller A, Crepaldi G, Fioretto P. Is podocyte injury relevant in diabetic nephropathy? Studies in patients with type 2 diabetes. Diabetes. 2003;52(4):1031-1035.

17. Griffin SV, Petermann AT, Durvasula RV, Shankland SJ. Podocyte proliferation and differentiation in glomerular disease: Role of cell-cycle regulatory proteins. Nephrol Dial Transplant. 2003;18(Suppl 6):vi8-13.

18. Wharram BL, Goyal M, Wiggins JE, et al. Podocyte depletion causes glomerulosclerosis: Diphtheria toxin-induced podocyte depletion in rats expressing human diphtheria toxin receptor transgene. J Am Soc Nephrol. 2005;16(10):2941-2952.

19. Shankland SJ, Pippin JW, Duffield JS. Progenitor cells and podocyte regeneration. Semin Nephrol. 2014;34(4):418-428.

20. Vogelmann SU, Nelson WJ, Myers BD, Lemley KV. Urinary excretion of viable podocytes in health and renal disease. Am J Physiol Renal Physiol. 2003;285(1):F40-48.

21. Petermann AT, Krofft R, Blonski M, et al. Podocytes that detach in experimental membranous nephropathy are viable. Kidney Int. 2003; 64(4):1222-1231.

22. Susztak K, Raff AC, Schiffer M, Bottinger EP. Glucose-induced reactive oxygen species cause apoptosis of podocytes and podocyte depletion at the onset of diabetic nephropathy. Diabetes. 2006;55(1): 225-233.

23. Eremina V, Quaggin SE. The role of VEGF-A in glomerular development and function. Curr Opin Nephrol Hypertens. 2004;13(1):9-15.

24. Fang L, Zhou Y, Cao H, et al. Autophagy attenuates diabetic glomerular damage through protection of hyperglycemia-induced podocyte injury. PLoS One. 2013;8(4):e60546.

25. Kriz W, Lemley KV. A potential role for mechanical forces in the detachment of podocytes and the progression of CKD. J Am Soc Nephrol. 2015;26(2):258-269.

26. Landau D, Israel E, Rivkis I, et al. The effect of growth hormone on the development of diabetic kidney disease in rats. Nephrol Dial Transplant. 2003;18(4):694-702.

27. Herbach N, Schairer I, Blutke A, et al. Diabetic kidney lesions of GIPRdn transgenic mice: Podocyte hypertrophy and thickening of the GBM precede glomerular hypertrophy and glomerulosclerosis. Am J Physiol Renal Physiol. 2009;296(4):F819-829.

28. Reddy GR, Pushpanathan MJ, Ransom RF, et al. Identification of the glomerular podocyte as a target for growth hormone action. Endocrinology. 2007;148(5):2045-2055.

29. Chitra PS, Swathi T, Sahay R, Reddy GB, Menon RK, Kumar PA. Growth hormone induces transforming growth factor-beta-induced protein in podocytes: Implications for podocyte depletion and proteinuria. J Cell Biochem. 2015;116(9):1947-1956.

30. Loeffler I, Wolf G. Epithelial-to-mesenchymal transition in diabetic nephropathy: Fact or fiction? Cells. 2015;4(4):631-652.

31. Dai HY, Zheng M, Tang RN, et al. Effects of angiotensin receptor blocker on phenotypic alterations of podocytes in early diabetic nephropathy. Am J Med Sci. 2011;341(3):207-214.

32. Yamaguchi Y, Iwano M, Suzuki D, et al. Epithelial-mesenchymal transition as a potential explanation for podocyte depletion in diabetic nephropathy. Am J Kidney Dis. 2009;54(4):653-664.

33. MerscherS, Fornoni A.Podocyte pathology and nephropathy:Sphingolipids in glomerular diseases. Front Endocrinol (Lausanne). 2014; 5:127.

34. Ishizawa S, Takahashi-Fujigasaki J, Kanazawa Y, et al. Sphingosine1-phosphate induces differentiation of cultured renal tubular epithelial cells under Rho kinase activation via the S1P2 receptor. Clin Exp Nephrol. 2014;18(6):844-852

35. Czyżewska-Buczyńska A, Konieczny A, Ryba M, et al. Zastosowanie nowych markerów wydalanych z moczem w diagnostyce wczesnego uszkodzenia nerek. Diagn Lab. 2013;49:239-245. 
36. Yu D, Petermann A, Kunter U, Rong S, Shankland SJ, Floege J. Urinary podocyte loss is a more specific marker of ongoing glomerular damage than proteinuria. J Am Soc Nephrol. 2005;16(6):1733-1741.

37. Konieczny A, Czyzewska-Buczynska A, Ryba M, et al. Expression of cell membrane antigens in cells excreted in the urinary sediment predicts progression of renal disease in patients with focal segmental glomerulosclerosis. Am J Nephrol. 2015;42(1):35-41.

38. Hara M, Yamagata $K$, Tomino $Y$, et al. Urinary podocalyxin is an early marker for podocyte injury in patients with diabetes: Establishment of a highly sensitive ELISA to detect urinary podocalyxin. Diabetologia. 2012;55(11):2913-2919.
39. Wang G, Lai FM, Lai KB, et al. Intra-renal and urinary mRNA expression of podocyte-associated molecules for the estimation of glomerular podocyte loss. Ren Fail. 2010;32(3):372-379.

40. Wang G, Lai FM, Lai KB, Chow KM, Li KT, Szeto CC. Messenger RNA expression of podocyte-associated molecules in the urinary sediment of patients with diabetic nephropathy. Nephron Clin Pract. 2007;106(4):c169-179.

41. Rossing $K$, Mischak H, Dakna M, et al. Urinary proteomics in diabetes and CKD. J Am Soc Nephrol. 2008;19(7):1283-1290.

42. Zurbig $P$, Jerums $G$, Hovind $P$, et al. Urinary proteomics for early diagnosis in diabetic nephropathy. Diabetes. 2012;61(12):3304-3313. 